\title{
O TRABALHO EM TEMPOS DE CRISE: BREVE REVISÃO TEÓRICA DO DEBATE ENTRE OS CONTEMPORÂNEOS
}

\author{
Recebido em 26/03/2021, aprovado em 9/06/2021 \\ 10.30612/mvt.v8i14.15022 \\ Cesar Sanson ${ }^{13}$
}

RESUMO: Teóricos dos estudos sobre o mundo trabalho identificam três mudanças em curso que vem provocando rupturas na sociedade do trabalho: a evolução das forças produtivas, o enfraquecimento do Estado como regulador da assimetria entre o capital e o trabalho e a financeirização da economia. Há uma crescente percepção que a sociedade salarial em sua versão fordista caracterizada pelo pleno emprego, estabilidade, renda satisfatória e previdência social já náo consegue incluir todos. O presente artigo apresenta uma breve síntese das abordagens teóricas, sobretudo no debate acadêmico, acerca da crise da sociedade salarial a partir de autores contemporâneos.

Palavras-chave: Trabalho. Sociedade assalariada. Inclusão social.

\section{WORK IN TIME OF CRISIS: BRIEF THEORETICAL REVIEW OF THE DEBATE AMONG CONTEMPORARY AUTHORS}

\begin{abstract}
Theorists of studies on the world of work identify three changes in progress that have been causing disruptions in the labor society: the evolution of the productive forces, the weakening of the State as a regulator of the asymmetry between capital and labor, and the financialization of the economy. There is a growing perception that the wage society in its fordist version characterized by full employment, stability, satisfactory income and social security is no longer able to include everyone. This article presents a brief synthesis of theoretical approaches, especially in the academic debate, about the crisis of the salaried society in contemporary authors.
\end{abstract}

Keywords: Work. Waged society. Social inclusion.

\section{EL TRABAJO EN TIEMPOS DE CRISIS: BREVE REVISIÓN TEÓRICA DEL DEBATE ENTRE CONTEMPORÁNEOS}

RESUMEN: Los teóricos de los estudios sobre el mundo del trabajo identifican três câmbios en curso que vienen provocando disrupciones em la sociedad laboral: la evolución de lâs fuerzas

\footnotetext{
13 Doutor pela Universidade Federal do Paraná (UFPR). Professor Associado, vinculado ao Departamento de Ciências Sociais na Universidade Federal do Rio Grande do Norte (UFRN). Área de pesquisa: Sociologia do Trabalho. E-mail: cesarsanson@gmail.com
} 
productivas, el debilitamiento del Estado como regulador de la asimetría entre capital y trabajo y la financiarización de la economía. Existe una percepción cada vez mayor de que la sociedad asalariada em su versión fordista caracterizada por el pleno empleo, la estabilidad, los ingresos satisfactorios y la seguridad social ya no es capaz de incluir a todos. Este artículo presenta una breve síntesis de los enfoques teóricos, especialmente en el debate académico, sobre la crisis de la sociedad asalariada de autores contemporáneos.

Palavras Clave: Trabajo. Sociedad asalariada. Inclusión social.

\section{INTRODUÇÃO}

Por muito tempo, ao menos a partir de meados do século XX, respirava-se certa convicção entre os pesquisadores do mundo do trabalho que caminhávamos para uma sociedade inclusiva, na qual o trabalho assalariado desempenharia papel central. Acreditava-se que o pêndulo capital versus trabalho chegaria a um ponto de equilíbrio, sobretudo pelas lutas operárias e pelo papel regulador do Estado. O pleno emprego associado a um rol de direitos, renda satisfatória e previdência social se estenderiam a todos e garantiriam uma sociedade socialmente justa sob a perspectiva da distribuição de renda. O que melhor representou essa ideia foi a sociedade fordista, período do pós-guerra que perdurou até os anos 1970, denominado de anos dourados do capitalismo. Há sinais, entretanto, que a sociedade fordista encontra-se em crise e não retornará mais. $\mathrm{O}$ assalariamento é cada vez mais escasso, o Estado se afasta do seu papel de árbitro contencioso na regulaçáo entre o trabalho e o capital e a previdência social se torna distante para um crescente número de pessoas. A vida no mundo de trabalho se faz cada vez mais pela intermitência, ganhos rebaixados e perda de direitos. A precarização no trabalho deixou de ser exceção e se tornou regra. Estamos diante de uma crise terminal da sociedade salarial? É possível retomar o pleno emprego? O Estado retomará o seu papel de regulador na assimetria trabalho-capital? Qual é o lugar do trabalho e a sua função social na sociedade hoje?

Esse debate - escancarado ainda mais pela pandemia do coronavírus - tem sido objeto de análise, entre outras áreas, na economia, na sociologia e no direito. Percebe-se uma crescente concordância entre os estudiosos da sociedade do trabalho que as mudanças em curso estáo associadas a três fatores: a evolução das forças produtivas, o enfraquecimento do Estado como regulador da relação capital-trabalho e a financeirização da esfera produtiva. Esses três movimentos simultâneos colocam em reviravolta a sociedade fordista. Assiste-se em todo o mundo a uma crescente instabilidade que ameaça a ideia do trabalho assalariado como porta de entrada para a inclusáo social.

O presente artigo expóe uma breve síntese do debate teórico acerca da crise da sociedade salarial a partir de autores contemporâneos. Apresenta-se, mesmo que sumariamente, as abordagens que se veem no debate, sobretudo acadêmico, acerca da crise da sociedade do trabalho. Incorpora-se nessa discussão, no contexto da pandemia da Covid-19, o debate da retomada da proposta de uma Renda Básica Universal (RBU) não apenas como mitigadora temporária dos efeitos da crise sanitária, mas como uma política pública permanente para responder à crise na sociedade do trabalho.

\section{CRISE DA SOCIEDADE SALARIAL: REVISÃO TEÓRICA DO DEBATE ENTRE OS CONTEMPORÂNEOS}

O trabalho regulado por um contrato em que se estabelece uma relação de troca - trabalho por salário - é datado historicamente. É a Revolução Industrial quem dá origem ao assalariamento.

A história já foi contada inúmeras vezes: como a expansão dos mercados, a presença do carvão e do ferro, assim como de um clima úmido propício à 
indústria do algodáo, a multidão de pessoas despojadas pelos novos cercamentos do século XVIII, a existência de instituições livres, a invenção das máquinas e outras causas interagiram de forma tal a ocasionar a Revolução Industrial. Já se demonstrou, conclusivamente, que nenhuma causa única merece ser destacada da cadeia e colocada à parte como 'à causa daquele acontecimento súbito e inesperado (POLANYI, 2000, p. 58-59).

Castel (1995) revela que a verdadeira descoberta que o século XVIII promove não é o da necessidade do trabalho, mas a da necessidade da liberdade do trabalho uma vez que a servidão é incompatível com os princípios liberais da burguesia emergente, ou seja, o trabalho doravante passa a ser vendido no mercado como outra mercadoria qualquer, porém, num âmbito de liberdade e náo compulsoriedade como foi a servidão. $\mathrm{O}$ autor afirma que agora com o advento da Revoluçáo Industrial o trabalho obedece à lei da oferta e da procura em que a relação que une o trabalhador a seu empregador tornou-se uma simples 'convenção', isto é, um contrato entre dois parceiros que se entendem sobre o salário. Esta transação, destaca, não é mais regulada por sistemas de coerção ou de garantias externas à própria troca. $\mathrm{O}$ mundo do trabalho vai mudar de base. É uma revolução na Revolução.

O trabalho regulado aos poucos vai se impondo e transformando a sociedade em uma sociedade salarial. $\mathrm{O}$ trabalho assalariado passa a ocupar um lugar central na vida das pessoas e marca decisivamente as relações de produção. Ainda mais, é através do trabalho que cada um tem a obrigação de dar um sentido à sua vida e à própria humanidade, como observa Saint-Simon, que viveu o alvorecer da Revolução Industrial:

O homem deve trabalhar. $\mathrm{O}$ mais feliz dos homens é aquele que trabalha. A família mais feliz é aquela na qual todos os seus membros empregam utilmente o seu tempo. A nação mais feliz é aquela na qual há menos desocupados. A humanidade gozaria toda a felicidade a que pode pretender se não houvesse ociosos (SAINT-SIMON apud GUYADER, 2005, p. 150).

O trabalho na sociedade industrial é elevado à condição de centro organizador da vida individual e coletiva: "Ele estrutura não somente a nossa relação com o mundo, mas também as nossas relaçôes sociais. Ele é a relação social fundamental” (MEDA, 1995, p. 26). Essa foi a grande transformação que se processa no final do século XVIII com a Revolução Industrial e intensifica-se no século XIX. O sistema de produção fordista no século XX é o coroamento da sociedade salarial em que a "sociedade se tornou fábrica" (NEGRI; HARDT, 2001).

O círculo virtuoso do fordismo - produção-renda-consumo - é um elemento distintivo da lógica do capital do século XX frente ao capital dos séculos XVIII e XIX. O capitalismo, em sua origem, não tinha como horizonte incluir os trabalhadores. Já o fordismo considera a inclusão dos trabalhadores, via consumo de massa, condição indispensável para o seu virtuosismo. O fordismo correspondeu aos anos dourados do capitalismo ${ }^{14}$ e, mais do que um simples modo de organizar

\footnotetext{
14 A expressão "anos dourados do capitalismo", período que vai do final dos anos 1940 até o início da década de 1970, é do historiador inglês Eric Hobsbawm (1997)ao comentar o crescimento virtuoso das economias americana e européia após a Segunda Guerra Mundial. Essas economias entraram num ciclo acelerado de crescimento tendo em sua base a sinergia entre o aumento de produtividade, salários e geração de empregos.
} 
a produção, correspondeu a um modo de vida. O capitalismo procura legitimar-se diante dos trabalhadores, fazendo do fordismo um sucesso que vincula um sistema de sociedade a um Estado regulador.

O que havia de especial em Ford (e que, em última análise, distingue o fordismo do taylorismo) era a sua visão, seu reconhecimento explícito de que produção de massa significa consumo de massa, um novo sistema de reprodução da força de trabalho, uma nova política de controle e gerência do trabalho, uma nova estética e uma nova psicologia, em suma, um novo tipo de sociedade democrática, racionalizada, modernista e populista (HARVEY, 2003, p. 121).

O fordismo, no seu momento histórico, encontra nas teses keynesianas ${ }^{15}$ - a necessidade de um Estado ativo e protagonista na regulação econômica - uma complementaridade. $\mathrm{O}$ fordismo fortalece o pensamento de Keynes e vice-versa, na medida em que o primeiro se propóe a estimular a produção, o consumo e o emprego; e o segundo sugere, para a supressão dos ciclos de depressão da economia, a pronta intervenção do Estado através de pesados investimentos. As ideias de Keynes, associadas ao fordismo e ao movimento operário em ascensão fundaram o Estado do Bem-Estar Social, com um leque de obrigaçôes.

$\mathrm{Na}$ medida em que a produção em massa, que envolvia pesados investimentos em capital fixo, requeria condiçôes de demanda relativamente estáveis para ser lucrativa, o Estado se esforçava por controlar ciclos econômicos com uma combinação apropriada de políticas fiscais e monetárias no período pósguerra. Essas políticas eram dirigidas para as áreas de investimento público em setores como o transporte, os equipamentos públicos etc. - vitais para o crescimento da produçấo e do consumo de massa e que também garantiam um emprego relativamente pleno. Os governos também buscavam fornecer um forte complemento ao salário social com gastos de seguridade social, assistência médica, educação, habitação etc. Além disso, o poder estatal era exercido direta ou indiretamente sobre os acordos salariais e os direitos dos trabalhadores na produção (HARVEY, 2003, p. 129).

A junção de dois movimentos poderosos - o fordismo e o keynesianismo - alavancaram um consistente e permanente desenvolvimento, principalmente no pós-guerra. É essa sociedade, a sociedade fordista, que agora se encontra em reviravolta. Dentre os principais fatores destacados pelos teóricos contemporâneos que estudam o trabalho três fatores simultâneos estão reconfigurando radicalmente a realidade da sociedade do trabalho. O primeiro deles é a ofensiva do capital frente ao trabalho. Assistimos a uma reversão daquilo que foi denominado de Estado de Bem-Estar Social do pós-guerra. O capital não admite mais a regulação e age para que toda a normatização da legislação que estabelece as regras entre o capital e o trabalho seja abolida. Cada vez mais as empresas passam a contar com uma legislação que permite ajustar sua produção, emprego, salário, jornada laboral e condiçóes de trabalho ante as flutuaçôes da economia. Observa-se um processo crescente de desregulamentação e eliminação de direitos.

15 Referência a John Maynard Keynes (1883 - 1946), economista britânico. Sua grande contribuição teórica, revisitando os clássicos da economia, foi a de demonstrar que o estado normal da economia é o desequilíbrio e náo o equilíbrio, e que a racionalidade individual leva a uma irracionalidade coletiva. Partindo do princípio de que Estado e mercado sáo duas instituiçóes complementares, defende a ideia de que a "mão invisível" do mercado necessita da "mão visível" do Estado. 
O segundo fator da desestruturação da sociedade salarial é a evolução das forças produtivas, particularmente a Revolução informacional e a Revolução 4.0, ambas, revoluçóes produtivas de grande envergadura. A Terceira Revolução Industrial, também denominada de Revolução Informacional ou Revolução Tecnológica tem o seu início a partir dos anos 1970. Surge da contracultura dos campi de universidades americanas, do desenvolvimento do parque industrial da Universidade Stanford e do Vale do Silício na Califórnia (EUA). Segundo Castells (1999), essa revolução reúne as seguintes características: 1 - Tecnologias que agem sobre a informação e não apenas informaçôes para agir sobre a tecnologia, como foi o caso das revoluçóes tecnológicas anteriores. 2 - Penetrabilidade dos efeitos das novas tecnologias - o novo meio tecnológico incide na existência individual e coletiva das pessoas. 3 - A lógica das redes - a possibilidade de estruturar o não estruturado, de criar interação. 4 - A flexibilidade - as novas tecnologias permitirão a reestruturação das organizaçóes sociais. 5 - Convergência das tecnologias para um sistema altamente integrado. Empresas tornam-se uma só: eletrônica/telecomunicaçóes/engenharia genética. A Quarta Revolução Industrial, também denominada de Revolução 4.0, é uma revolução do século XXI e distingue-se das anteriores pela capacidade de estabelecer a fusão de tecnologias e a interação entre os domínios físicos, digitais e biológicos. Entre as principais inovaçôes em curso, encontram-se: inteligência artificial, robótica, internet das coisas, veículos autônomos, impressão em 3D, ampliação de pesquisas e inovaçôes nas áreas de nanotecnologia e biotecnologia. Essas inovaçóes estão em curso e vêm alterando significativamente a sociedade do trabalho. Embora, os seus resultados não sejam ainda perceptíveis em seu conjunto, é incontestável a potência da introdução desses novos recursos tecnológicos. Tome-se como exemplo as plataformas digitais, resultantes da inteligência artificial, que deram origem a categoria dos trabalhadores de aplicativos.

Essas revoluçóes produtivas de grande monta são comparáveis em seus impactos às mudanças produzidas pela Revolução Industrial. Ao contrário, entretanto, da Revolução Industrial do século XVIII que empregou milhares de pessoas, essas revoluçóes produtivas não requerem mais o trabalho de todos. Elas se fazem na crescente dispensa de trabalho particularmente na indústria e o crescimento de trabalho no setor de serviços. Os novos empregos desse setor são, porém, majoritariamente precários, como se veem, por exemplo, nos calls centers e nas plataformas de trabalho digital como trabalhadores de aplicativos.

O capitalismo produtivo que permanece ancorado nas indústrias, por sua vez, exige sempre e cada vez mais mão de obra qualificada, que tenha capacidade de agregar conhecimento ao processo produtivo na perspectiva do aumento da produtividade, condiçáo indispensável num mercado altamente competitivo. É a denominada economia do imaterial, uma economia que transfere importância, em termos de valorizaçáo, para os ativos imateriais, aqueles relacionados ao universo da intangibilidade, ou seja, ao conhecimento, às ideias, ao domínio das novas tecnologias da informação. Esses ativos são recursos cada vez mais utilizados no processo produtivo. Situam-se, porém, nessa condição de domínio do trabalho imaterial poucos trabalhadores, aqueles que trabalham em nichos produtivos de alta tecnologia. Logo, o que vemos com a mudança no paradigma produtivo é a desestruturação do mercado ocupacional. Observa-se que a sociedade homogênea do trabalho fordista cede lugar a uma crescente instabilidade em que trabalhadores são substituídos por máquinas, ao mesmo tempo em que se instala a precariedade, intermitência, flexibilizaçáo de direitos e ganhos reduzidos.

Finalmente, outra mudança que corrói a sociedade do trabalho destacada pelos estudiosos é a supremacia do capital financeiro sobre o capital produtivo. As empresas, hoje, principalmente as grandes corporaçôes, respondem sempre e cada vez mais aos interesses de investidores e acionistas. 
Na sociedade industrial clássica, o empresário retornava parte do seu lucro para a sociedade através do pagamento de salários e geração de empregos com a abertura de novas unidades fabris. Agora, com uso intensivo de tecnologia, as empresas aumentam a produtividade, pagando menos salários e empregando menos. O dinheiro que, antes, voltava parcialmente para a sociedade, é transferido para o mercado financeiro.

Resumindo, verifica-se que desde os finais dos 1970 mudanças significativas se processam no capitalismo conforme caracterizado por Castells (1999): a) fortalecimento do capital frente ao Estado - manifestadamente perceptível na integração global dos mercados financeiros; formação de blocos econômicos; b) concorrência econômica global acompanhada pela descentralizaçáo das empresas, com o objetivo de globalizar sua produção para aumentar seus ganhos; c) erosáo do EstadoNação e o seu (re)direcionamento para desfazer o contrato do bem-estar social; d) desintegraçáo do mercado de trabalho associada a dois movimentos: a crise do chamado processo de produçáo padronizado e a irrupção da produção flexível e a desregulamentação do aparelho normativo das leis que sustentavam um determinado tipo de organização do trabalho; e) transformação da estrutura ocupacional, na qual se assiste a um declínio do emprego industrial em benefício do emprego precário no setor de serviços; f) papel e lugar da política que sofre um processo de fragilização; na redefinição de valores culturais que colocam em crise as instituiçóes.

O caráter das mudanças em curso na sociedade industrial e o seu significado assumem na literatura sociológica contemporânea várias denominaçóes: "sociedade pós-industrial", "pós-fordista" em Lazzarato e Negri (2001), Virno (2002) e Rulani (1998); “capitalismo cognitivo” em Vercellone (2011), Corsani (2003), Moulier-Boutang (2003), Cocco (2003); "sociedade do conhecimento" em Gorz (2005); "sociedade informacional” em Castells (1999) e Lojkine (1999); "era do acesso" em Rifkin (2001); "segunda modernidade" em Giddens (2002); "pós-social” em Touraine (2006); "pós-modernidade” em Harvey (2003); "novo capitalismo” em Sennett (2006); “modernidade líquida" em Bauman (2001) e "sociedade do risco" em Beck (2010). Esses conceitos, entre outros, expressam não necessariamente uma oposição entre si, mas antes de tudo, formas próximas para dar conteúdo a um mesmo acontecimento: o enfraquecimento do paradigma da sociedade salarial/ industrial.

As mudanças em curso no capitalismo re-colocaram, portanto, em debate o lugar que o trabalho ocupa na organização econômica e social da sociedade. Esse debate, particularmente do enfraquecimento e da crise da sociedade salarial, surge nos países centrais, sobretudo na França, estimulado principalmente pela produção teórica de Gorz (1987). De acordo com Langer (2003) Gorz parte da tese de que historicamente o trabalho nem sempre foi aquilo que ele é hoje. O que nós nos acostumamos a chamar de trabalho subsumido ao emprego é uma criação da modernidade. A forma sob a qual o conhecemos, praticamos e o situamos no centro da vida individual e social, foi criada, e em seguida generalizada com a sociedade industrial. A racionalização do trabalho para sua vertente emprego segundo Gorz (1998, p. 36),

foi uma revolução, uma subversão do modo de vida, dos valores, das relaçôes sociais e da natureza, em essência, a invenção no sentido pleno do termo de algo que nunca havia existido. A atividade produtiva foi esvaziada de seu sentido, de suas motivaçóes e de seu objeto para tornar-se simples meio de ganhar um salário. Ela deixou de fazer parte da vida para tornar-se o meio de 'ganhar sua vida'. O tempo de trabalho e o tempo de viver foram separados; o trabalho, seus instrumentos, seus produtos adquiriram uma realidade separada da do trabalhador e a depender de decisóes estranhas. 
O que está em crise é, pois, uma determinada forma de trabalho, o emprego, o assalariamento, e não o trabalho no sentido antropológico. De acordo com Gorz as razóes da crise do trabalho assalariado, do emprego, encontram-se, sobretudo na evolução das forças produtivas, da instauração da Revolução Informacional que maximiza a produtividade e poupa mão de obra. Na perspectiva gorziana a sociedade do pleno emprego não retornará mais:

É preciso ousar querer o Êxodo da 'sociedade do trabalho': ela não existe mais e não voltará. É preciso querer a morte desta sociedade que agoniza, com o fim de que outra possa nasce sobre seus escombros. É preciso aprender a distinguir os contornos desta sociedade diferente detrás das resistências, das disfunçōes, dos becos sem saída dos quais está feito o presente (GORZ, 1997, p. 11).

Entre os autores que "acompanham" a argumentaçáo de Gorz acerca crise do assalariamento podemos identificar, entre outros, Rifkin (1995), Offe (1995), Méda (1995), Gollain (2000), Robin (1993), Sue (1997). Esses autores, grosso modo, estão de acordo com Gorz e afirmam que as transformaçôes do capitalismo mundial, particularmente a partir da evolução das forças produtivas e da perda da força política do Estado como regulador do mercado de trabalho, levaram a uma crise do trabalho assalariado em que os anos dourados do capitalismo ficaram para trás e a sociedade do pleno emprego não retornará.

Essa tese da crise da sociedade salarial, do assalariamento, ou ainda do emprego náo é acompanhada, entretanto, por uma série de outros autores. Destaca-se aqui, sobretudo Castells (1999) que contesta as "profecias apocalípticas" daqueles que afirmam que estamos diante do fim do emprego. Castells concorda que se assiste a uma redução do emprego industrial, resultante da Revolução Informacional, mas que esse declínio do assalariamento industrial é compensado pela ampliação de postos de trabalho no setor de serviços, sobretudo naquele potencializado pela nova dinâmica da economia informacional. Ainda entre os autores que contestam a perda da centralidade do trabalho e, para ficar em mais dois exemplos, um da França e outro do Brasil, encontram-se Castel (1995) e Antunes (1999). Castel reconhece que a centralidade do trabalho vem sendo colocada em questáo e com ela todo o suporte de identidade social e pertencimento à sociedade. O autor comenta que há um novo crescimento de "vulnerabilidade de massa" que se pensava afastado. Assim como o pauperismo do século XIX estava inserido no coração da dinâmica da primeira industrialização, também a precarização do trabalho é um processo central, comandado pelas novas exigências tecnológicas da evolução do capitalismo moderno, diz ele. Três pontos da cristalização da nova questão social podem ser distinguidos afirma Castel (1995): 1 - desestabilização dos estáveis: classe operária integrada e assalariados da pequena classe média ameaçadas (a mobilidade ascendente se desfaz); 2 - instalação da precariedade: trajetórias erráticas feitas de alternância de emprego e não emprego; 3 - déficit de lugares: trabalhadores que não têm mais lugar no processo produtivo. $\mathrm{O}$ núcleo da questão social seria hoje, segundo Castel, o retorno dos desfiliados - aqueles que estão fora da sociedade salarial. Porém, indaga: $\mathrm{O}$ surgimento da nova questão social nos permite afirmar que a sociedade salarial morreu? É possível recolocar no jogo social as populaçôes invalidadas pela conjuntura e acabar com uma hemorragia de desfiliação que ameaça deixar todo exangue o corpo social? Segundo Castel, estamos diante de uma bifurcação: aceitar uma sociedade inteiramente submetida às exigências da economia ou reconstruir um Estado Social à altura dos novos desafios. Isto porque, diz ele, nas últimas décadas o Estado que na Revolução Industrial moderna ganhou papel de regular as relaçóes mercado-trabalho, hoje perde esta função e a economia se autonomizando desagrega a condição salarial. Castel, portanto, acredita na possibilidade de reconstituição da 
inclusão via o trabalho a partir de um decisivo papel do Estado que interceda para o equilíbrio em sua relação com o capital.

Antunes (1999), por sua vez, também reconhece que há uma desestruturação da sociedade salarial. Segundo o autor, a classe trabalhadora no século XXI, em plena era da globalização, é mais fragmentada, mais heterogênea e ainda mais diversificada. Acrescenta que neste processo acentua-se uma perda significativa de direitos que em sintonia com o caráter destrutivo do capital vigente tornou o trabalho ainda mais precarizado, intensificando os níveis de exploração para aqueles que trabalham. A partir dessa conformação mais fragmentada e mais heterogênea, o autor sugere uma noção ampliada de trabalho que define como o conceito 'classe-que-vive-do-trabalho' para configurar a nova classe trabalhadora. Antunes incorpora os que estáo fora do assalariamento tradicional, como os trabalhadores informais, no conjunto dos assalariados sob o argumento de que também vendem a força de trabalho. Logo, o autor sugere uma leitura do trabalho em que não haja uma dicotomização entre assalariamento e não assalariamento porque compreende, principalmente a partir das economias periféricas, que essa divisão é redutora do conceito de classe trabalhadora.

Destaque-se que a diferença de análise entre os autores citados e os anteriores é a interpretação sobre a crise do assalariamento. Enquanto Gorz e outros consideram que caminhamos para o fim do assalariamento tal qual se convencionou no fordismo; Castells, Castel e Antunes discordam dessa tese e reafirmam que embora seja incontestável o processo de reestruturaçáo do capitalismo a partir do último quarto do século $\mathrm{XX}$, não se pode falar em fim do assalariamento.

Entre os autores que acentuam a desestruturação da sociedade salarial fordista destaca-se Harvey (2003). O autor inaugura o conceito da 'acumulação flexível', um padrão de produção que se ajusta a nova dinâmica do capitalismo a partir da crise do fordismo dos anos 1970. Segundo o autor, esse padrão produtivo

se apóia na flexibilidade dos processos de trabalho, dos mercados de trabalho, dos produtos e padróes de consumo. Caracteriza-se pelo surgimento de setores de produção inteiramente novos, novas maneiras de fornecimento de serviços financeiros, novos mercados e, sobretudo, taxas altamente intensificadas de inovação comercial, tecnológica e organizacional (HARVEY, 2003, p. 140).

De acordo com o Harvey, as características desse novo modo produtivo são as seguintes: 1 - a organização industrial que antes se pautava na produção em larga escala passa por uma drástica transformação e a produção em escopo passa a superá-la; 2 - essa forma de produçáo em pequenas quantidades ancoradas no método just in time permite alcançar públicos cada vez mais específicos e acompanhar as rápidas transformaçóes dos padróes de consumo; 3 - a esta tendência está aliado o fenômeno da subcontratação e as fusóes de grandes corporações; 4 - a subcontrataçáo possibilita uma maior flexibilidade dos contratos, como a grande empresa não tem um vínculo direto com o trabalhador, dispensá-lo é muito simples; 5 - as empresas combinam quantidade de empregados em tempo integral com habilidades facilmente encontradas no mercado de trabalho que se caracteriza por uma alta taxa de rotatividade, bem como os de profissionais altamente capacitados, que ganham altos salários mas substituem, com suas habilidades de operar e fiscalizar linhas de produçáo automatizadas, grandes quantidades de trabalhadores fixos sem qualificaçáo.

O debate da reestruturação do capitalismo até então lastreado no padrão flexível de produção e as suas consequências, é também intenso entre os estudiosos brasileiros com a particularidade de que destacam que essa nova dinâmica é ainda mais devastadora na estrutura ocupacional de economias periféricas. Entre outros autores, muito ativos nesse debate, destacam-se: Antunes (2013), já 
citado; Braga (2012) Pochmann (2001), Leite (1994), Krein (2001; 2019), Alves (2000), Ramalho e Santana (2009), Véras (2011), Druck (2007), Filgueiras (2004). Todos eles acentuam a ofensiva do capital frente ao trabalho destacada por Harvey e sinalizam para um trinômio deletério: flexibilização, terceirização e precarização, tudo isso chancelado pelo Estado, que num processo gradativo, desde os anos 1980, subordina-se aos interesses do capital. O que há em comum na leitura desses autores é o fato de que as mudanças em curso na sociedade do trabalho indicam uma ruptura com o período industrial anterior que distribuía os ganhos de produtividade através do assalariamento. Segundo os autores, assistimos a uma ofensiva nas últimas décadas do capital frente ao trabalho que se manifesta através da alteração das normas que se ajustam às condiçôes do mercado: contrato de trabalho, remuneração e jornada de trabalho. Simultaneamente, alertam, vemos o crescimento da ideologia do empreendedorismo onde a uberizaçâa ${ }^{16}$ do trabalho vai se tornando a nova lógica em que a regra é a ausência de regras. Esses autores não falam em esgotamento da sociedade salarial, mas admitem a sua severa crise e propugnam na linha de Castel (1995) que é imprescindível a retomada do papel do Estado como um agente indutor do equilíbrio social que reconstitua o seu papel em defesa do trabalho. O problema, afirmam, é que cada vez mais se observa a retirada do Estado em sua função de contenção da exacerbação dos interesses do capital. É nessa perspectiva que acentuam que as Reformas, entre elas e, principal, a Reforma Trabalhista ${ }^{17}$, como emblemática de uma nova ordem de aniquilação da proteção ao trabalho. Não está explícito e necessariamente não há uniformidade entre os autores, mas percebe-se que os mesmos defendem a retomada do 'sistema do trabalho fordista' que recupere a ideia da estabilidade no trabalho, ou seja, a regularidade e não a intermitência; renda satisfatória e a reconstituição do rol de direitos de proteção ao trabalho, incluindo a previdência social.

Acerca das mudanças na sociedade do trabalho há uma particular reflexão, sugerida por Sennett (1999, 2006). O autor não entra em cheio no debate sobre a crise ou não do assalariamento, mas destaca as mudanças de caráter ético-cultural advindas das transformaçôes em curso. Sennett destaca que a velha ética no mundo do trabalho está sendo substituída por outra ética. Segundo o autor, se anteriormente o trabalho era caracterizado por um processo padronizado - fordista - na qual se exigia um trabalhador especializado e a produtividade era alavancada pela somatória das performances individuais, hoje se busca uma organização social do trabalho flexível. A percepção de Sennett é que, sob a perspectiva ética, a nova sociedade do trabalho, resultante das mudanças estruturais do capitalismo, bagunçou tudo. A vida do trabalho perdeu sua narrativa linear. De acordo com Sennett (1999, 2006), as novas características da sociedade de trabalho são: 1 - A deriva, a nova maneira de organizar o tempo de trabalho é que se acabou o "longo prazo". O emprego está sendo substituído por "projetos' e "campos de trabalho". Náo há mais longo prazo e a sua ausência corrói a confiança, a lealdade e o compromisso mútuo. 2 - Instala-se o sentimento do "fantasma da inutilidade", a ideia de que as pessoas são facilmente substituíveis, sejam pelas máquinas, seja pela insuficiência de qualificação. 3 - A rotina. A sociedade moderna, diz Sennett, está em revolta contra o tempo rotineiro, burocrático. A rotina pode degradar, mas também proteger; pode decompor o trabalho, mas

\footnotetext{
16 Conceito que denota a veloz tendência das novas modalidades e condiçóes de trabalho oriundas das inovaçôes tecnológicas, transformadas em aplicativos que possibilitam a prestação de serviços através da interação entre o digital, o físico e o biológico. A condição de trabalho na uberização é caracterizada pela ausência de regulação. É intrínseco ao modelo a não vinculação com direitos trabalhistas tal e qual se conheciam na sociedade industrial fordista. Comumente, associa-se uberização ao conceito de precarização que manifesta, além da ausência de direitos regulados, baixa remuneração e jornadas de trabalho extensas.

17 Reforma aprovada em 2017 pelo Congresso brasileiro e sancionada pelo governo de Michel Temer que alterou substancialmente a Consolidação das Leis do Trabalho (CLT).
} 
também compor uma vida. Hoje, no novo mundo do trabalho, ganha centralidade a necessidade de indivíduos flexíveis, que estejam sempre à disposição da lógica do mercado. 4 - A flexibilidade. Agora todos são instados a serem flexíveis. Ser flexível significa aqui se adaptar a circunstâncias variáveis, trata-se de assumir uma postura de administração do tempo, o 'flexi-tempo'. 5 - O risco. Essa é outra característica do novo mundo do trabalho. O risco torna-se uma necessidade diária, pois a instabilidade das organizaçóes flexíveis impóe aos trabalhadores a necessidade de correr riscos, de assumir iniciativas que nem sempre apresentam perspectiva de segurança que darão certo. 6 - $\mathrm{O}$ fracasso. Outro aspecto presente no novo mundo do trabalho. Pergunta Sennett, "como se sentem os demitidos"? Segundo a narrativa do autor, no início, se sentiam vítimas passivas da empresa, num segundo momento culpavam a economia global, e por último, expressam o fracasso pessoal com a carreira pelo fato de não terem tomado esta ou aquela decisão no decorrer de sua vida profissional. A percepção de Sennett (1999) é a de que no novo mundo do trabalho há uma "corrosão do caráter", ou seja, a construção identitária em torno do trabalho durante quase dois séculos está se esvaindo.

Segundo Sennett, as mudanças em curso alteram a estabilidade no trabalho que se via no fordismo a partir várias dinâmicas. Agora, a vida no trabalho se faz cada vez mais de intermitências, as atividades laborais são de breve contratação definida na maioria das vezes por tarefas, empreitadas, projetos como se vê através da denominada pejotização do trabalho, situação na qual o trabalhador deve ser tornar um empreendedor e estabelecer contrato com o contratante para trabalhos terceirizados e majoritariamente de caráter temporário. A interpretação de Sennett, portanto, é a de que no novo mundo do trabalho há uma "corrosão do caráter", ou seja, a construção identitária em torno do trabalho constituída durante quase dois séculos está se esvaindo.

Outro debate sobre as mudanças de fundo da sociedade salarial/industrial é aquele que se vincula ao conceito do "capitalismo cognitivo", "pós-fordismo" ou "sociedade pós-industrial". Autores, entre outros, como Negri e Hardt (2001), Lazzarato (2001), Corsani (2003), Virno (2002), Cocco (2003) destacam que no epicentro do deslocamento do capitalismo industrial para o pós-industrial, encontra-se a economia do imaterial e do trabalho imaterial com profundas inflexóes sobre a sociedade do trabalho. Em contraponto ao 'trabalho morto' da sociedade industrial assiste-se a emergência do 'trabalho vivo'. A essência do capital produtivo da sociedade pós-industrial, sugerem os autores, se vale cada vez menos de um controle sobre os corpos e as vidas e investe nas vidas e nos corpos como capacidades produtivas singulares - o 'trabalho vivo'. Investe não mais para subordiná-los, adestrá-los e controlá-los, mas para ativar sua cooperação subjetiva e possibilitar a produção do comum - a somatória das performances individuais que torna possível o plus produtivo numa economia extremada pela competitividade. O caráter "revolucionário" do trabalho imaterial, destacado pelos autores citados anteriormente, é reafirmado por Hardt e Negri (2005, p. 156) ao citarem que o trabalho agora se assenta no fato de que "as formas centrais de cooperação produtiva já não são criadas pelo capitalista como parte do projeto para organizar o trabalho, mas, emergem das energias produtivas do próprio trabalho". Esses autores não discutem a crise do trabalho assalariado, mas ao indicarem o deslocamento da natureza do trabalho que hoje se realiza, evidenciam que o modelo fordista se esgotou. Destacam, os autores, que com o advento do capitalismo cognitivo, a teoria valor marxista tende a ser deslocada para diferentes formas de trabalho que rompem com as horas de trabalho efetivamente verificadas para coincidir cada vez mais com o tempo geral da vida. Em outras palavras, o conceito emprego enquanto unidade pré-estabelecida de uma jornada de trabalho padrão com produtora de valor (mais valor) rompeu-se.

Ainda sobre os transtornos que sofre o trabalho assalariado-industrial identifica-se outra posição no debate teórico. Trata-se daquele propugnado pelos autores que abordam a emergência 
do capitalismo financeiro que se sobrepóe ao capitalismo produtivo e passa a "organizar" a economia. Encontram-se aqui autores como Roggero (2009), Vercellone (2011), Fumagalli (2010) e Marazzi (2009). Para eles, a financeirização assumiu as rédeas da economia real, do capital produtivo. Ainda mais: a financeirização de uma função suplementar ao capital produtivo passou a incidir e decidir a econômica real, subordinando-a. Nesse sentido, a financeirização - deixou de contrapor-se à economia real com algo dicotômico - e assumiu a forma econômica capitalista por excelência. $\mathrm{O}$ capitalismo produtivo náo se dissocia mais do capitalismo financeiro e antes disso, é o segundo que estabelece a dinâmica do primeiro. Fumagalli (2010) destaca que no paradigma atual do capitalismo cognitivo, o mercado financeiro, deixou de ser o local de rendimento parasitário improdutivo e passou a ser o motor da economia. Segundo ele, a centralidade do mercado financeiro se manifesta em duas dinâmicas:

Eles [mercado financeiro], de fato, proveem o financiamento da atividade de acumulação, sobretudo no caso das produçóes cognitivas imateriais (conhecimento e espaço) e, em segundo lugar, na presença de mais-valias, desenvolvem o papel de multiplicador da economia e de redistribuição da renda. Trata-se de um multiplicador financeiro que induz uma distorção da renda diversamente daquele real keynesiano baseado no 'deficit spending' (FUMAGALLI, 2010, p. 11).

Ou seja, doravante vivemos uma relação permanente de débito-crédito em que o risco de insolvência das dívidas é constitutivo ao crescimento da base financeira e ao mesmo tempo em que sufoca a base produtiva, desloca o papel antes exercido pelo Estado na oferta dos serviços públicos para a esfera privada com mercantilização dos mesmos serviços.

\section{CRISE DO TRABALHO, PANDEMIA E ALTERNATIVAS}

Como observamos anteriormente, através de diferentes autores, assiste-se nas últimas décadas a uma radical reconfiguração da sociedade do trabalho. A essa reconfiguração soma-se uma crise sanitária que atingiu severamente o já fragilizado mundo do trabalho. Em todo o mundo milhares de trabalhadores foram impedidos de continuar o seu trabalho e afastados de suas atividades, muitos foram demitidos e tantos outros sofreram mutilaçôes salariais (IBGE, 2021). A pandemia Covid-19 agravou a condição daqueles que dependem do seu trabalho para sobreviver, sobretudo nos países mais pobres. A devastação provocada pela crise sanitária na sociedade do trabalho colocou em relevo a necessidade de políticas públicas de mitigação àqueles que ficaram sem renda. Neste contexto foi retomado o debate sobre a proposta da criação de uma Renda Básica Universal (RBU), também denominada de Renda Básica Cidadã (RBC) ou Renda Mínima Universal (RMU). A ideia, grosso modo, é de que as pessoas recebam uma renda mensal satisfatória para prover a vida em suas condiçóes básicas uma vez que se encontram sem trabalho.

A instituição em muitos lugares de uma renda emergencial e temporária em função da situação de calamidade provocada pela pandemia Covid-19 recolocou em discussão a proposta de uma renda permanente para todas as pessoas. Um dos primeiros propositores da ideia foi Gorz (2004) para quem se tornou insustentável vincular renda ao emprego em função da crise do assalariamento. Gorz sugere entáo uma espécie de mínimo vital, uma renda universal e incondicional desvinculada do trabalho assalariado. A ideia parte do pressuposto de que cada vez haverá menos empregos e as 
pessoas precisam continuar vivendo. $\mathrm{O}$ interesse por essa proposta ganhou espaço sobretudo nos países desenvolvidos ou ricos ao longo da última década - há várias experiências em curso -e mesmo nos países mais pobres ou em desenvolvimento se têm versôes inspiradas nessa ideia, como o caso do Bolsa Família brasileiro. Destaque-se, porém, que há uma distinção entre renda mínima e auxílios emergenciais e temporários que são políticas compensatórias voltadas para os que se encontram em situação de extrema pobreza e a renda básica que, por sua vez, se propóe universal, incondicional e permanente. Essa renda seria destinada a todos, num valor razoável e capaz de garantir acesso às exigências básicas para uma vida satisfatória.

Entre os autores propagadores e defensores da proposta se encontram Van Parjis (2006), Raventós (2014) e Standing (2017). Em comum, os autores argumentam que a proposta de uma Renda Básica pode se constituir num programa que assegure para todas as pessoas da sociedade, independente de trabalhar ou não, um rendimento de inclusão social, uma espécie de salário social, provido pelo Estado que dê as pessoas o mínimo de autonomia e independência.

\section{CONCLUSÃO}

A Revolução Industrial com o advento do assalariamento deu forma a um potente mecanismo de inclusão social, àquele que se realiza através de uma atividade laboral estável, com renda satisfatória e um conjunto de direitos. Essa construção social se constituiu de meados do século XVIII até o penúltimo quarto do século XX. O Welfare State é a melhor expressão desse construto e passou a ser um modelo a ser perseguido, ou seja, a tríade Capital-Trabalho-Estado se retroalimentando e produzindo inclusão e justiça social. Duas características marcam decisivamente o caráter do Welfare State: o pleno emprego e a previdência social.

Esse modelo, entretanto, dá sinais crise. A sociedade salarial encontra cada vez mais dificuldades em incluir todos, considerando-se o crescente contingente daqueles que estão fora do assalariamento. O breve resgate do debate teórico entre autores contemporâneos apresentada nesse artigo revela essa constatação. Entre os autores citados há denominadores comuns; o principal deles, o de que aquela sociedade industrial se encontra em radical metamorfose. As mudanças em curso, como se pode verificar no debate estão vinculadas a três movimentos: 1- a anulação do papel do Estado como árbitro no contencioso entre o capital versus o trabalho. 2 - a evolução das forças produtivas que alteram substancialmente o modo produtivo permitindo produzir mais e empregando menos e, 3 - a financeirização da economia real, um processo no qual há um deslocamento dos investimentos do capital produtivo para o capital financeiro.

A partir dos autores citados pode se depreender do conjunto do debate que a sociedade salarial-industrial já não consegue ou encontra severas dificuldades em sua função, até então histórica, de incluir as pessoas pelo emprego, pela renda assalariada e pela previdência social. A questáo de fundo que se coloca, portanto, é o debate sobre o que eventualmente poderia socorrer a sociedade salarial em sua incapacidade de oferecer oportunidade a todos. É nesse debate e, impulsionada pela pandemia da Covid-19, que ressurge com força a proposta da Renda Básica Universal; não apenas como mecanismo de mitigação temporária aos efeitos devastadores da crise sanitária, mas como instrumento permanente de atender ao crescente número de pessoas que já não conseguem sua inclusão social via assalariamento convencional. 


\section{REFERÊNCIAS}

ALVES, Giovanni Alves. O Novo (e precário) Mundo do Trabalho. São Paulo: Boitempo, 2000.

ANTUNES, Ricardo.Os sentidos do trabalho: ensaio sobre a afirmaçáo e a negaçáo do trabalho. São Paulo: Boitempo, 1999.

Riqueza e Miséria do Trabalho no Brasil II. São Paulo: Boitempo, 2013.

BAUMAN, Zygmunt. Modernidade Líquida. Rio de Janeiro: Zahar, 2001.

BECK, Ulrich. Sociedade do Risco - Rumo a uma outra modernidade. São Paulo: Editora 34, 2010.

BRAGA, Ruy. A política do precariado: do populismo à hegemonia lulista. São Paulo: Boitempo, 2012.

CASTEL, Robert. As metamorfoses da questão social: uma crônica do salário. Petrópolis: Vozes, 1995.

CASTELLS, Manuel. A Sociedade em Rede. São Paulo: Paz e Terra, 1999.

COCCO, Giuseppe; GALVÃO, Alexander Patez; SILVA, Gerardo; (Orgs). Capitalismo cognitivo. Rio de Janeiro: DP\&A editora, 2003.

CORSANI, Antonella. Elementos de uma ruptura: a hipóteses do capitalismo cognitivo. In: GALVÃO, Alexander Patez; SILVA, Gerardo; COCCO, Giuseppe (Orgs). Capitalismo cognitivo.Rio de Janeiro: DP\&A editora, 2003. p. 15-32.

DRUCK, Graça. Perda da Razáo Social do Trabalho. São Paulo: Boitempo, 2007.

FILGUEIRAS, Luiz; DRUCK, Graça; AMARAL, Manoela. O conceito de informalidade: problema ou solução - um exercício de aplicação empírica dos conceitos. Caderno CRH, Salvador, vol. 17, n. 41, p. 211-229, 2004.

FUMAGGALI, Andrea. As finanças no comando bioeconômico do trabalho vivo. In: Biocapitalismo e trabalho. Novas formas de exploração e novas possibilidades de emancipação. IHU ON-LINE, São Leopoldo, ano X, n. 327, p.11-13, 2010.

GIDDENS, Anthony. Modernidade e Identidade. Rio de Janeiro: Zahar, 2002.

GOLLAIN, Françoise. Une critique du travail: entre écologie et socialismo. Paris: La Découverte, 2000.

GORZ, André. Adeus ao Proletariado: para além do socialismo. 2ª ed. Rio de Janeiro: Forense-Universitária, 1987.

Misères du présent. Richesse du possible. Paris: Galilée, 1997.

Métamorphoses du travail: quête du sens. Critique de la raison économique. Paris: Galilée, 1988.

O imaterial. São Paulo: Annablume, 2005. 
GUYADER, Alain Le. Claude-Henri de Saint-Simon: nascimento do intelectual orgânico da sociedade industrial. In: MERCURE, Daniel; SPURK, Jan. (orgs.). O trabalho na história do pensamento ocidental. Petrópolis (RJ): Editora Vozes, 2005. pp. 137-166.

HARVEY, David. Condição Pós-moderna. 13a ed. São Paulo: Loyola, 2003.

HOBSBAWM, Eric. A era dos extremos. O breve século XX 1914-1991. 2a ed. São Paulo: Companhia das Letras, 1997.

IBGE. Pnad Covid-19. Disponível em: https://covid19.ibge.gov.br/pnad-covid/. Acesso em: 26 jun. 2021.

KREIN, José Dari. O aprofundamento da flexibilização das relaçóes de trabalho no Brasil nos anos 90. Dissertação (Mestrado em Economia Social e do Trabalho) - Programa de Pós-Graduação em Economia Social e do Trabalho, Instituto de Economia, Universidade Estadual de Campinas, Campinas, SP, jan. 2001.

; VERAS, Roberto (orgs). Reforma Trabalhista no Brasil: Promessas e Realidade. São Paulo: Editora Remir, 2019.

LANGER, André. Pelo êxodo da sociedade salarial: a evoluçáo do conceito de trabalho em André Gorz. Dissertação (Mestrado em Ciências Sociais) - Programa de Pós-Graduação em Ciências Sociais Aplicadas, Centro de Ciências Humanas, Universidade do Vale do Rio dos Sinos - São Leopoldo, RS, dez. 2003.

LAZZARATO, Maurizio; NEGRI, Antonio. Trabalho imaterial. DP\&A Editora: Rio de Janeiro, 2001.

LEITE, Márcia Paula. O Futuro do Trabalho. São Paulo: Scritta, 1994.

LOJKINE, Jean. A Revoluçáo Informacional. São Paulo: Cortez Editora, 1999.

MARAZZI, Christian. O Lugar das Meias. Rio de Janeiro: Civilização Brasileira, 2009.

MÉDA, Dominique. Le travail: une valeur en voie de disparition. Paris: Aubier, 1995.

MOULIER-BOUTANG, Yann. O território e as políticas de controle do trabalho no capitalismo cognitivo. In: GALVÃO, Alexander Patez; SILVA, Gerardo; COCCO, Giuseppe (Orgs). Capitalismo cognitivo. Rio de Janeiro: DP\&A Editora, 2003, p. 33-61.

NEGRI, Antonio; HARDT, Michael. Império. Rio de Janeiro - São Paulo: Record, 2001.

Multidáo. Rio de Janeiro - São Paulo: Record, 2005.

OFFE, Claus. Capitalismo desorganizado. 2. ed., 1. reimpr. São Paulo: Brasiliense, 1995.

POCHMANN, Marcio. A década dos mitos: o novo modelo econômico e a crise do trabalho no Brasil. São Paulo: Contexto, 2001.

POLANYI, Karl. A grande transformação: as origens da nossa época. 2. ed. Rio de Janeiro: Campus, 2000.

RAMALHO, José Ricardo; SANTANA, Marco Aurélio. Sociologia do Trabalho - Ciências Sociais Passo a Passo. São Paulo-Rio de Janeiro: Jorge Zahar, 2009. 
RAVENTÓS, David. La renta basicaenla era de las grandes desigualdades. Barcelona: Montesinos, 2014.

RIFKIN, Jeremy. O fim dos empregos: o declínio inevitável dos níveis dos empregos e a redução da força global de trabalho. São Paulo: Makron Books, 1995.

. A era do acesso. São Paulo: Makron Books, 2001.

ROBIN, Jacques. Os caminhos para uma sociedade de "plena atividade" e não mais de "pleno emprego". Revista de debate político, Salvador, n. 6, p. 135-145, 1993.

ROGGERO, Gigi. Capitalismo cognitivo. A financeirização, em crise, é a sua forma econômica real. In: O capitalismo cognitivo e a financeirização da economia. Crise e horizontes. IHU ON-LINE, São Leopoldo, ano IX, n. 301, p.05-09, 2009.

RULLANI, Enzo. Dal fordismo realizzato ao postfordismo possible: la difficile transizione. In: RULLANI, Enzo; ROMANO, Luca. Il postfordismo. Milão: Etaslibri, 1998. p. 2-80.

SENNETT, Richard. A Corrosão do Caráter. Conseqüências pessoais do trabalho no novo capitalismo. São Paulo: Record, 1999.

. A cultura do novo capitalismo. São Paulo - Rio de Janeiro: Record, 2006.

STANDING, G. Basic Income: And How We Can Make It Happen. Pelican Books: 2017.

SUE, Roger. La richesse des hommes: vers l'économie quaternaire. Paris: Odile Jacob, 1997.

TOURAINE, Alain. Um novo paradigma. Para compreender o mundo de hoje. Petrópolis: Vozes, 2006.

VANDERBORGHT, Yannick; VAN PARJIS, Philippe. Renda básica de cidadania: Argumentos Éticos e Econômicos. Rio de Janeiro: Civilização Brasileira, 2006.

VERAS DE OLIVEIRA, Roberto. Para discutir os termos da nova informalidade: sobre sua validade enquanto categoria de análise na era da flexibilização. In: OLIVEIRA, Roberto; GOMES, Darcilene; MOREIRA, Ivan (org.). Marchas e contramarchas da informalidade do trabalho: das origens às novas abordagens. João Pessoa: Editora Universitária da UFPB, 2011. p. 191-228

VERCELLONE, Carlo. Capitalismo cognitivo. Buenos Aire: Editora Prometeo, 2011.

VIRNO, Paolo. Grammaire de la multitude. Quebéc: Conjectures \& l'éclat, 2002. 